\title{
Floral Patches and Their Impact on Pollinator Attraction and Yield Production on Cucurbita maxima Var. Paine in Central Chile
}

\author{
Santiago Donoso ${ }^{1}$ and Maureen Murúa ${ }^{2, *}$ (D) \\ 1 Escuela de Agronomía, Facultad de Ciencias, Universidad Mayor, Camino La Pirámide 5750, \\ Santiago 8580745, Chile; santiago.donoso@mayor.cl \\ 2 Centro GEMA: Genómica, Ecología y Medio Ambiente, Facultad de Estudios Interdisciplinarios, \\ Universidad Mayor, Camino La Pirámide 5750, Santiago 8580745, Chile \\ * Correspondence: maureen.murua@umayor.cl
}

Citation: Donoso, S.; Murúa, M. Floral Patches and Their Impact on Pollinator Attraction and Yield Production on Cucurbita maxima Var. Paine in Central Chile. Diversity 2021, 13, 608. https://doi.org/10.3390/ d13120608

Academic Editor: Michael Wink

Received: 22 October 2021

Accepted: 22 November 2021

Published: 24 November 2021

Publisher's Note: MDPI stays neutral with regard to jurisdictional claims in published maps and institutional affiliations.

Copyright: (c) 2021 by the authors. Licensee MDPI, Basel, Switzerland. This article is an open access article distributed under the terms and conditions of the Creative Commons Attribution (CC BY) license (https:/ / creativecommons.org/licenses/by/ $4.0 /)$.

\begin{abstract}
In recent decades, it has been shown that pollination deficit can significantly affect crop production. Moreover, now it is known that the appropriate management of pollination can increase the quantity and quality of yields. Therefore, pollination appears to be a key component in modern agriculture. This study aimed to determine the impact of floral patch addition on the quality and quantity of Cucurbita maxima fruit production. To this end, we manually added a set of ornamental plant species to the edge of the crop and monitored the pollinator diversity and visit frequency, as well as the seed set and sugar content of the pumpkin yield, in treatment and control parcels. The results showed that there was a higher visit rate in the treated parcel. Only the sugar content, and not the seed set, was affected by the addition of ornamental species and the pollinator visit rate. These findings indicate that the addition of flowering plants can favor different components of the crop yield of this species, but future studies should sample on a broader spatial and temporal scale in order to certify the generalizability of our results.
\end{abstract}

Keywords: biodiversity; crop system; Cucurbitaceae; food security; pollination

\section{Introduction}

Traditionally, when crop productivity problems are observed, hydric and nutrient regimes are immediately reviewed, but pollination deficit is rarely considered. Studies conducted over the last decade have determined that a pollination deficit in crops can be even more damaging than a deficit in resources such as water and nutrients, since these resources are easier to manage compared to pollination [1]. Moreover, today it is known that the appropriate management of pollination can increase the quantity and quality of crop yield [2,3]. For example, in canola crops (Brassica napus) it has been observed that a greater diversity of pollinating insects improves the oil content in its seeds [4]. Additionally, improvements in pollinator management also increase the size, color, and firmness of apples, strawberries, and blueberries [5-9]. Therefore, pollination appears to be a key component in modern agriculture.

It is estimated that around $75 \%$ of all agricultural crops in the world depend to some degree on animal pollination, and that 35\% of the total crop production necessary for human consumption is favored by animal vectors [10]. In fact, several crops important to human nutrition and health in terms of vitamins and minerals input (e.g., vitamin $\mathrm{C}$ and A, calcium, and carotenoids [9]) are highly dependent on animal vectors for their pollination [11]. Unfortunately, pollinator abundance and diversity are declining at an accelerating rate [12], which in the medium-to-long term would cause a deficit between the amount of food required in the world and the total amount that can be produced [13].

Faced with the threat of pollinator diversity loss worldwide, researchers have dedicated themselves to finding solutions through which to increase both pollinator abundance 
and diversity in different crop systems. In modern agriculture, some techniques have been developed mainly to provide suitable habitats for pollinators [14]. These include sowing native or wildflower seeds at field edges, or improving soil quality and increasing populations of wild pollinators through the vegetation adjacent to crops [15].

In particular, sowing wild flowers at the crop edge has emerged as a promising management strategy, since it favors the maintenance of alternative floral resources for a longer time than several pollinating insects. Recent studies have shown that flower patch incorporation can increase the abundance of pollinators [16,17], favoring crop yield in some orchards [18]. However, unknown the effect of this strategy on many other crop systems is unknown, especially those where highly pollinator-dependent herbaceous species are grown.

According to FAO, pollination is essential for the production of approximately $11 \%$ of the main commercial crops on the planet, including fruit trees and vegetables such as mango (Mangifera indica), kiwi (Actinidia deliciosa), custard apple (Annona cherimola), and pumpkin (Cucurbita maxima), among others [19]. In particular, as a monoecious crop, cucurbits stand out as animal vectors that are essential for fertilization [20]. In Chile, C. maxima is one of the most important cucurbits, since it is one of the five vegetables with the largest cultivated area in the country (approximately 5000 hectares [19]). However, recent conversations with local farmers have indicated that its crop yield has decreased recently. They suggest that this phenomenon has several causes, $\mathrm{w}$ one of which is the lack of efficient pollinators, since honeybees do not always fertilize pumpkin flowers effectively (Murúa, pers. obs). The latter argument is supported by a recent study on Cucurbita pepo that revealed that supplementing pumpkin individuals with commercial A. mellifera does not increase either their visitation frequency or fruit production compared to individuals in non-supplemented fields [3].

In light of this information, we present a study to determine the impact of the addition of floral patches on the quality and quantity of fruit production of Cucurbita maxima var. Paine. We predicted that the addition of floral patches would increase pollinator diversity and consequently increase the seed set and sugar content of pumpkins. To test this, we performed a manipulative experiment in which ornamental plant species were situated at the edges of a crop. Subsequently, we monitored the visitation frequency of each pollinator species and the quality and quantity of pumpkin yield in treatment and control conditions.

\section{Materials and Methods}

\subsection{Study System}

C. maxima var. Paine is a crop originating in South America; it is highly cultivated, mainly due to its nutritional properties and its long storage period [21]. It has a creeping or climbing habit with rough, hollow, and angular stems with the presence of tendrils (Figure 1a). The flowers feature a yellow corolla, with large petals and a cylindrical peduncle ([22], Figure 1b). Female flowers feature three staminodia, a short style, and between three and five bilobed stigmas, while ovaries typically include three, but sometimes $4-5$, carpels. The male flower grows on a long peduncle with anthers attached [22]. The flowering period is particularly short as flowers are open and receptive for only one day. The fruits are large, generally spheroidal, of grayish-green color on the outside and with an orange pulp on the inside (Figure 1c,d). It features a low water content, and a high content of carbohydrates and carotenoid compounds. This makes pumpkin a crop of great importance to the country. Generally, it is sown during the spring months, followed by flowering and fruiting in early summer. 


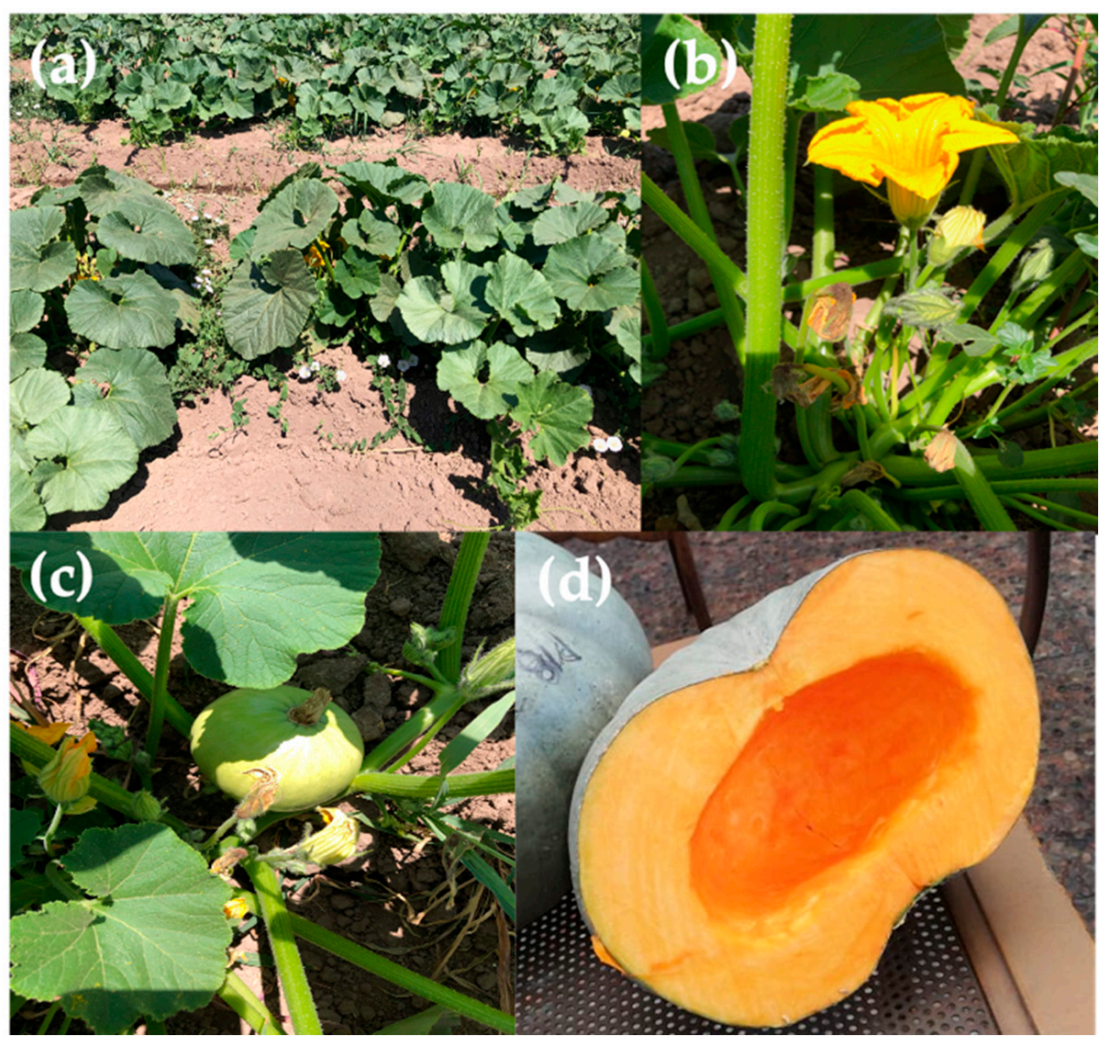

Figure 1. Habitus (a), flower morphology (b) and fruit development (c,d) of Cucurbita maxima var. Paine at the study site.

\subsection{Study Site}

The study was conducted during spring-summer season from September 2019 to January 2020, covering the entire growing period of the crop. The sampling was located in an orchard of approximately 20 hectares located in the commune of Alto Jahuel, Buin, Chile ( $\left.33^{\circ} 44^{\prime} 48.5^{\prime \prime} \mathrm{S}, 70^{\circ} 41^{\prime} 38.9^{\prime \prime} \mathrm{W}\right)$. The farmland was divided into six parcels; in each, one different species was cultivated separately, including Juglans regia, Zea mais, and Prunus persica var. nucipersica, in addition to C. maxima var. Paine and C. maxima var. Diaguita. From these, two parcels were selected to conduct the experiments and monitoring, in which only C. maxima var. Paine grew separated by a Zea mais crop, with a distance of approximately $500 \mathrm{~m}$ between them.

\subsection{Experimental Design}

To determine the impact of the addition of flower patches on the production of the C. maxima crop, a manipulative experiment was designed. To do this, two parcels of approximately $120 \mathrm{~m}$ per $25 \mathrm{~m}$ approximately were selected and designed as control (C) and treated (T1) plot (i.e., floral patches plantation). In each one, 20 individuals of C. maxima (approximately 2-3 individuals per row), equally spaced, were selected and marked. Subsequently, every $10 \mathrm{~m}$ at the edges of the T1 plot, a floral patch was planted. The patches consisted of six ornamental species, which were in bloom at the same time as the crop. The selection of species was made based in their coloration and plant structures, taking care to include species of different colors and floral displays (e.g., individual flowers and/or inflorescences). The patches were found to be composed of Lavandula latifolia, Cosmos bipinnatus, Salvia splendens, Lobelia erinus, Tagetes patula, and Leucanthemum vulgare (Figure 2). The patches were watered twice a week, and each was given approximately four liters for the duration of the study. 


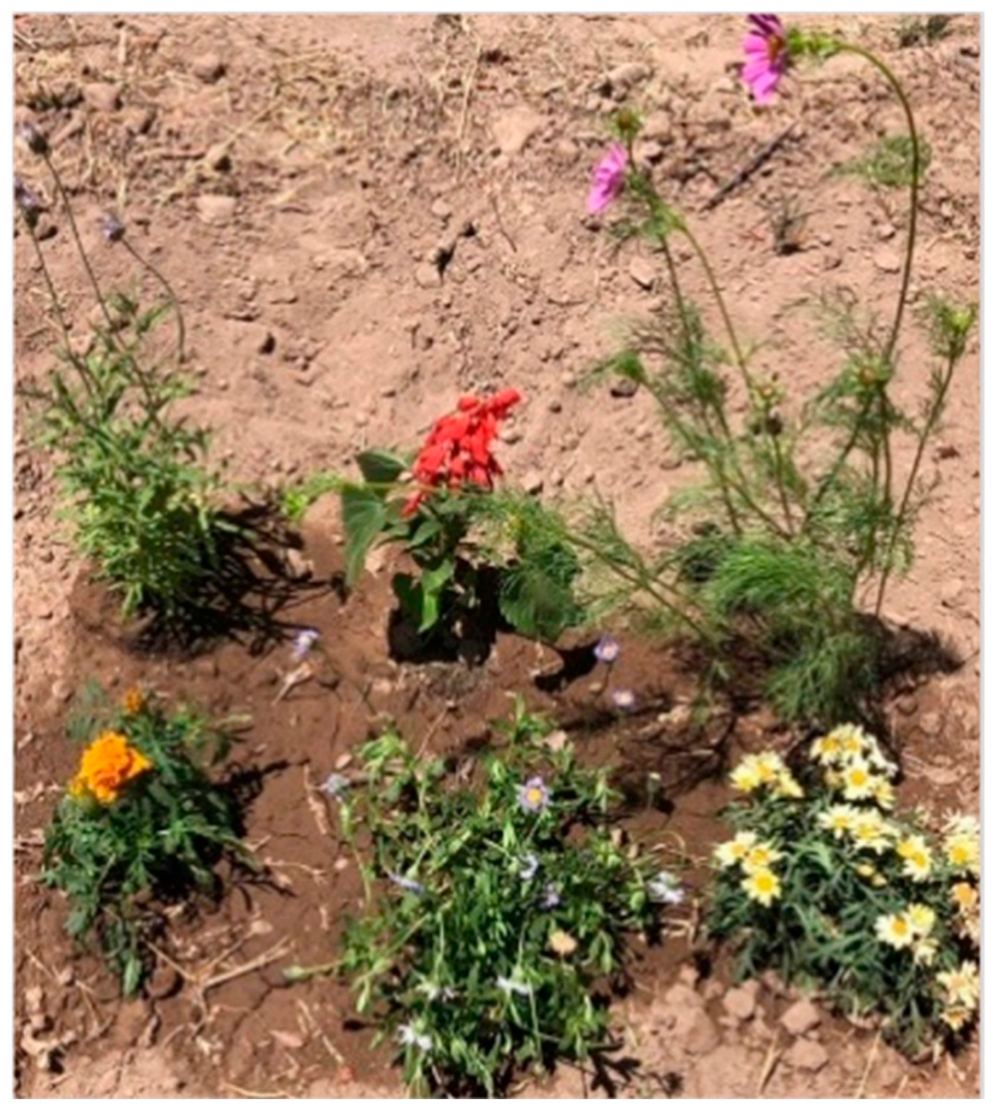

Figure 2. Floral patches installed in the Cucurbita maxima var. Paine crop.

\subsection{Characterization of Pollinator Assemblages}

To characterize the composition of the pollinator species assemblages in both plots, we conducted a visitation frequency recording during the entire month of $C$. maxima's flowering. Twice a week for four consecutive weeks, we performed a census on each marked plant in both parcels in the hottest hours (i.e., 11:00-14:00 h). The censuses were performed for $15 \mathrm{~min}$ and the activity of each insect that visited the marked plants was recorded. Only those insects that touched the reproductive structures of the plants were considered legitimate pollinators. The insects were identified at the lowest possible taxonomic level directly in the field, and only those specimens that were not easily identified were brought to the laboratory for consultation with a specialist. Finally, the visitation rate was estimated as the number of visits per flower per unit of time.

\subsection{Quality and Quantity of Crop Yield}

In January 2020, once fruiting occurred, each marked pumpkin was harvested and taken to the laboratory to measure variables that accounted for the quantity and quality of the crop yield. We decided to use the seed number per fruit as a proxy for yield quantity as it was expected that the pollinator's presence would alter the pollen depositions in the stigmatic surface, affecting the ovule fecundation and, consequently, the seed set. In terms of quality, we decided to use solids in pulp, since in Chile pumpkin sweetness is a key characteristic that determines the preference of costumers. In addition, we measured the weight of each C. maxima to be used as a covariate in the subsequent analysis. The measurements were performed with a precision mechanical balance and expressed in grams.

The quantity component was estimated as the number of seeds produced per fruit. For this, each fruit was cut lengthwise, its seeds extracted from the seminal cavity and counted. Next, from each cut individual, a pulp sample was extracted, ground with a mortar, and the liquid content filtered with a fine mesh of $150 \mu \mathrm{m}$. Subsequently, a sample of $2 \mathrm{~mL}$ of that liquid portion was taken with a pipette and applied in an optical refractometer to 
measure the Brix degrees, which represented the grams of saccharose in $100 \mathrm{~g}$ of solution and was expressed as a percentage.

\subsection{Data Analysis}

To determine the impact of floral addition on the abundance of pollinating insects, an analysis of variance (ANOVA) was carried out using the visitation frequency as a response variable and treatments as a factor. Furthermore, to explore the impact of floral addition on the quantity and quality variables, we performed two independent Generalized Linear Model (GLM) analyses. For each GLM, the quantity and quality variables were used as a response variable, and the treatments as factors. Interaction terms were also tested, but only those statistically significant are reported.

Finally, to determine the joint effect of floral addition on the pollinator's attraction and, consequently, on the quantity and quality of C. maxima production, we performed two new independent GLM analyses. The first GLM, seed set per fruit, was used as a response variable using a Poisson-type distribution. Regarding pulp density, it was transformed from a percentage to a continuous variable, using it as a response variable with a Poisson-type distribution. In both analyses, the visit rates were used as a factor and individual weight as a covariate. The ANOVA and GLM analyses were performed in R Studio software version 1.1453 [23].

\section{Results}

\subsection{Characterization of Pollinator Assemblages}

The pollinator assemblages were composed of a few pollinator species, which differed between plots. In the control plot, the honeybee Apis mellifera and the bumblebee Bombus terrestris were the only pollinating species. In the treated plot (T1), two hymenopteran (A. mellifera and Manuelia gayi), one coleopteran (Eriopis sp.) and one dipteran (Sirphidae sp.) composed the total pollinator group. Regarding the pollinators' abundance, we recorded 323 interactions between C. maxima flowers and their pollinator species, among which 218 visits were registered in plot T1, approximately double the number of those registered in the control plot (105 visits).

Examining the visitation frequency, on average, we observed that the mean visitation rate in the control plot was half that of the registered in plot $\mathrm{T} 1$ (Table 1), which was a statistically significant difference (ANOVA: $Z=0.62, t$-value $=3.71, p=0.001$ ). In both plots, the exotic honeybee A. mellifera was the species that made most of the visits, registering an average visit rate of 0.56 visits $\times$ flower $^{-1} \times \mathrm{h}^{-1}$ in the control and 1.07 visits $\times$ flower $^{-1} \times \mathrm{h}^{-1}$ in the T1 plot, respectively. In addition, the second species that performed the most visits to $C$. maxima in the control plot was the exotic bumblebee B. terrestris $\left(0.17\right.$ visits $\times$ flower $\left.^{-1} \times \mathrm{h}^{-1}\right)$, while in the experimental plot $\mathrm{T} 1$ it was the native solitary bee $M$. gayi, with a visit rate of 0.13 visits $\times$ flower $^{-1} \times \mathrm{h}^{-1}$.

\subsection{Quantity and Quality of C. maxima Production}

In general, with the exception of the number of seeds, in the treated plot the pumpkins had a greater weight and were sweeter (i.e., high ${ }^{\circ}$ brix) than those present in the control situation (Table 1). In particular, the individuals weighed $\sim 600 \mathrm{~g}$ more in the treated plot than in the control one (Figure 3), differences that were statistically significant (GLM: $Z=$ $0.13, t$-value $=27.88, p<0.001)$.

The seed set was similar between the plots and no significant differences were observed between treatments (GLM: $Z=0.01, t$-value $=0.34, p=0.74$ ). By contrast, the mean percentage of soluble solids in pulp present in the liquid portion of $C$. maxima were higher in the T1 plot than in the control plot (Figure 4), differences that were statistically significant (GLM: $\mathrm{Z}=0.11, t$-value $=9.19, p<0.001$ ). 
Table 1. Visitation rate, fruit weight, seed set, and solid solutes in pulp of C. maxima var. Paine in both experimental plots. Mean values and standard deviation are shown.

\begin{tabular}{|c|c|c|c|c|}
\hline Plot & $\begin{array}{c}\text { Visitation Rate } \\
\left(\mathrm{n}^{\mathrm{o}} \text { Visit } \times \text { Flower }^{-1} \times \mathrm{h}^{-1}\right)\end{array}$ & $\begin{array}{l}\text { Fruit Weight } \\
\quad(\mathrm{kg})\end{array}$ & $\begin{array}{c}\text { Seed Set } \\
\left(n^{\circ} \text { Seed per Fruit) }\right.\end{array}$ & $\begin{array}{c}\text { SP } \\
\left({ }^{\circ} \text { Brix }\right)\end{array}$ \\
\hline \multirow[t]{18}{*}{ Control } & 0.63 & 2.7 & 209 & 4.2 \\
\hline & 1.00 & 2.6 & 267 & 5.0 \\
\hline & 0.75 & 5.0 & 410 & 7.6 \\
\hline & 0.88 & 5.0 & 232 & 9.0 \\
\hline & 0.88 & 4.2 & 246 & 7.0 \\
\hline & 0.25 & 3.2 & 200 & 5.4 \\
\hline & 0.5 & 6.0 & 217 & 8.0 \\
\hline & 0.63 & 4.3 & 178 & 5.9 \\
\hline & 0.33 & 5.0 & 286 & 7.0 \\
\hline & 0.50 & 4.9 & 202 & 8.1 \\
\hline & 0.31 & 3.1 & 114 & 8.0 \\
\hline & 1.25 & 6.0 & 257 & 9.0 \\
\hline & 1.00 & 4.2 & 124 & 6.0 \\
\hline & 0.25 & 4.3 & 189 & 8.1 \\
\hline & 0.38 & 3.3 & 270 & 5.0 \\
\hline & 0.38 & 5.1 & 266 & 7.6 \\
\hline & 0.63 & 8.4 & 291 & 8.6 \\
\hline & 0.42 & 3.3 & 289 & 6.2 \\
\hline Mean \pm SD & $0.61 \pm 0.29$ & $4.5 \pm 1.43$ & $236 \pm 68.05$ & $6.98 \pm 1.47$ \\
\hline \multirow[t]{18}{*}{ Treatment 1} & 1.75 & 5.0 & 204 & 8.1 \\
\hline & 1.25 & 5.3 & 240 & 9.7 \\
\hline & 1.38 & 4.3 & 190 & 8.0 \\
\hline & 1.58 & 4.2 & 246 & 8.0 \\
\hline & 2.75 & 4.9 & 262 & 9.6 \\
\hline & 1.50 & 6.0 & 228 & 8.0 \\
\hline & 0.88 & 5.9 & 198 & 11.0 \\
\hline & 0.38 & 5.1 & 128 & 7.9 \\
\hline & 1.50 & 4.2 & 248 & 7.6 \\
\hline & 0.33 & 5.0 & 191 & 8.7 \\
\hline & 0.50 & 5.1 & 235 & 9.0 \\
\hline & 0.70 & 5.1 & 214 & 7.0 \\
\hline & 1.92 & 7.0 & 304 & 7.1 \\
\hline & 1.25 & 5.0 & 232 & 8.5 \\
\hline & 1.33 & 6.8 & 264 & 9.1 \\
\hline & 1.50 & 3.4 & 216 & 7.0 \\
\hline & 0.40 & 5.9 & 308 & 9.0 \\
\hline & 0.88 & 4.0 & 331 & 7.3 \\
\hline Mean $\pm S D$ & $1.21 \pm 0.63$ & $5.1 \pm 9.41$ & $236 \pm 48.38$ & $8.37 \pm 1.07$ \\
\hline
\end{tabular}

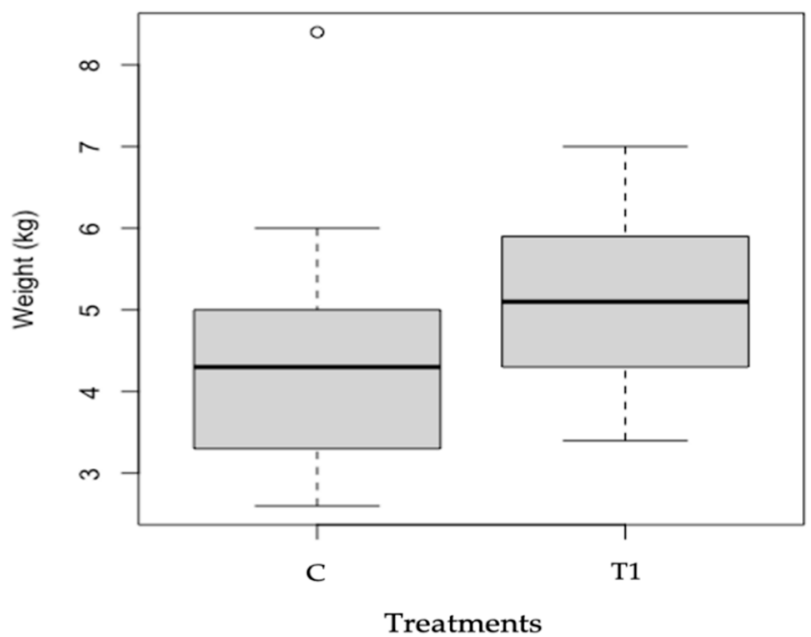

Figure 3. Weight of Cucurbita maxima var. Paine individuals in both study plots. C= control, T1: Treatment 1 . 


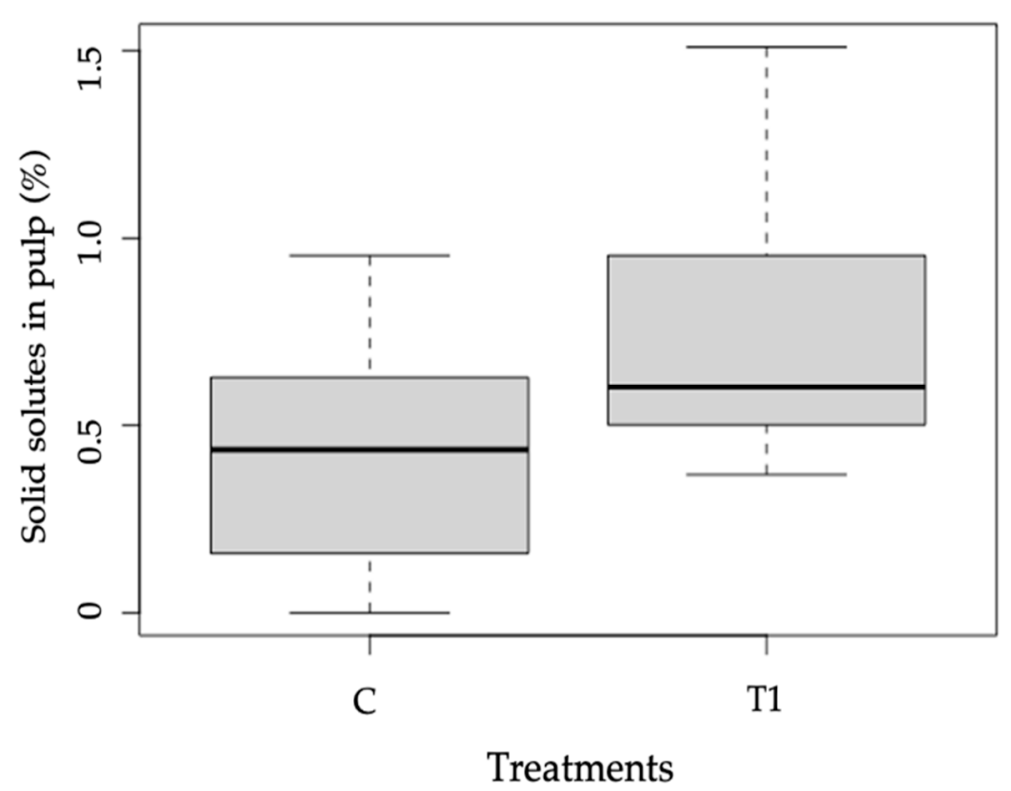

Figure 4. Percentage of solid solutes in the pulp of fruits of Cucurbita maxima var. Paine in both plots under floral patches addition treatment. $\mathrm{C}=$ control, T1: Treatment 1 .

\subsection{Pollinators and Their Impact on C. maxima Production}

In the analysis of the effect of treatments and visitation frequency of pollinator species on the quantity component of the production, no significant effects were observed from either the treatments or the visit rate on seeds per fruit; only the covariate showed a significant difference (Table 2). For the analysis of the quality component, we observed significant effects of treatments, visitation frequency of pollinators, pumpkin weight, and most of the interaction terms among them on the soluble solids in the pulp of $\mathrm{C}$. maxima (Table 2).

Table 2. Summary of the GLM effect of treatment, visit rate, fruit weight, and its interaction terms on seed set and soluble solids in the pulp of Cucurbita maxima. N represents sample size. ${ }^{* *} p<0.01$, *** $p<0.001$.

\begin{tabular}{cccc}
\hline Seed Set $(\mathbf{N}=\mathbf{1 8})$ & Estimate & Z Value & $p$ Value \\
\hline Treatment $(\mathrm{T})$ & -0.04 & -0.22 & 0.82 \\
Visit rate $(\mathrm{VR})$ & 0.09 & 0.56 & 0.58 \\
Weight $(\mathrm{W})$ & 0.001 & 2.48 & $0.01^{* *}$ \\
\hline Soluble Solids in Pulp (N = 18) & & & \\
\hline Treatment (T) & 0.19 & 8.84 & $<0.001^{* * *}$ \\
Visit rate (VR) & -0.34 & -3.86 & $<0.001^{* * *}$ \\
Weight (W) & 0.001 & 4.22 & $<0.001^{* * *}$ \\
T $\times$ VR & 0.17 & 0.48 & 0.63 \\
T $\times$ W & 0.02 & -9.42 & $<0.001^{* * *}$ \\
VR $\times$ W & 0.001 & 4.02 & $<0.001^{* * *}$ \\
\hline
\end{tabular}

\section{Discussion}

The main aim of this study was to determine the impact of the addition of floral patches on the attraction of pollinators that can improve the quantity and quality of C. maxima crop. The results obtained in the focal census showed that the pollinator assemblages were composed of a few insect species, whose visitation frequency differed between the experimental plots. In addition, the pumpkin weight and pulp sweetness, but not the seeds per fruit, were higher in the treated plot than in the control plot. The analysis of the join impact of pollinator species and floral patch addition on the quality and quantity 
component of C. maxima production showed that visit rate and treatments can affect solid solutes in pulp, but not the number of seeds per fruit. These results suggest that the addition of other floral resources, complementary to the crop, can not only favor the frequency of visitation to these flowers, but could also contribute to enhancing the quality of crop production.

\subsection{Effect of the Addition of Flower Patches on the Diversity and Frequency of Pollinator Visits}

Our results showed that the addition of floral patches to the edge of the pumpkin crop can favor the attraction of a few new pollinator species. In addition, it was possible to observe a greater frequency of visits to flowers in cultivation in the treated plot compared to the control situation. These findings coincide with the results of several other studies, where an increase in both diversity and pollination frequency has been documented [11,17,24-26]. For example, in Scotland [17] on Rubus idaeus (raspberry) crops it was observed that the addition of a strip of wild flowers increased the abundance of species present in the crop by $25 \%$. Likewise, in Israel, in a study carried out on a Citrullus lanatus crop between 2009 and 2011 [26], it was determined that the addition of floral patches increased the presence and visitation of wild pollinators, but not of honeybees.

In the present study, we recorded three non-Apis species in the treated plot, in which the solitary bee $M$. gayi was the second most frequent pollinator species in that plot. $M$. gayi, like the rest of the species of its genus, is a polylectic bee that forages several native and exotic plant species. In addition, it is a species that builds nests in logs following a solitary pattern, which consists in the construction of galleries in which it provides food for the young larvae that develop in partitioned cells [27]. To date, there are no records of visits by this species to any other species in cultivation in Chile, nor are there records of its domestication and use as a commercial pollinator. However, according to its foraging habits and wide distribution throughout the country, it is possible that this species is a potentially good pollinator for different crop species. However, as for all native bee pollinators in Chile, its efficiency and contribution to plant pollination still needs to be studied.

Some studies have reported positive results from surrounding vegetation in orchards in terms of an improvement in pollinators' attraction and diversity (reviewed in [28]). Although we were able to observe an increase in species richness in the treated plot, this increase was only of a few species and in low abundance, which may be explained by at least three factors that are not mutually exclusive.

First, the origin, size, and composition of the patches might not be the most appropriate to attract more local pollinators, since the plant species used to conform them were ornamental, and the patches were small; the patches might also might have been unattractive or unknown to many insects, and they may not have offered the insects an appropriate nutritional content. Previous studies indicated that there is a direct relationship between the size of flower patches that are established in the surroundings of crops and the diversity and abundance of pollinators [29].

Second, another important factor is the time over which this research was developed. According to the phenology of C. maxima, we performed a study that lasted only two months, so it is likely that it was not possible to detect differences in abundance because the insects did not have enough time to recognize the new surrounding flora. Possibly, if the patches had been installed a few months before the pumpkins bloomed, the plants would have established themselves and attracted more insects over time. Studies conducted in C. pepo have highlighted the importance of the establishment time of floral cords in the detection of changes in visitation frequency to cultivated plants [30]. In fact, in the study carried out by [17], the authors detected changes in the diversity of pollinators only after several months or even years, which highlights the importance of time to establish a permanent diversity of insect species in orchards.

Third, another relevant factor may have been the presence of nectarine trees that were close to the crop and a living fence that delimits the property. Both featured open flowers 
in the same flowering period of $C$. maxima, and the insects might have preferred to visit these flowers than those of the crop itself.

\subsection{Effect of Pollinators on Quality and Quantity in the Production of C. maxima}

The results demonstrated that both flower addition and pollinator visitation can affect the quality, but not the quantity, of C. maxima production. Here, the amount of solid solutes in the pulp of C. maxima was higher in the plot with floral patches; this plot also featured a higher visitation rate by pollinator species. Fruit quality has been evaluated a few times in some cultivar species (e.g., cucumber, strawberry, pearl, among others), leading to the suggestion that the presence of pollinators improves fruit shape, firmness, and shelf life, and reduce fruit acidity $[6,31,32]$, which seems to be an indirect effect of hormone secretion after successful pollination [6]. However, these patterns were found under different experimental conditions (i.e., the absence and presence of pollinators), and, most of the time, self-pollination produces fruits of lower quality. Unfortunately, our experimental approach was different, preventing us from making an appropriate comparison between our results and those of previous studies.

In our study, floral addition attracted three more insect species in the treated plot that were not present in the control plot, which might have complemented the pollination performed by A. mellifera, ensuring an appropriate fecundation and increased fruit sweetness. Different investigations have shown that wild pollinators can perform a more efficient pollination than A. mellifera [33,34] or complement it by forcing them to move forward between plant lines in some orchards [35], suggesting the important complementary role of native species in crop yield. Here, we were not able to determine the pollination efficiency of those non-Apis species to establish their real contribution to crop pollination. To our knowledge, this has never been explored in cucurbits species, so the beneficial effects of different animal vectors on sugar contents or other quality variables is still unknown and deserves to be explored further.

Unlike fruit quality, the impact of pollinators on yield production has been explored many times for different crops [36]). In the case of the Cucurbitaceae family, other researchers have shown that, on average, pollinator richness increases final crop production [36,37], which would be explained by the susceptibility of these species to suffering pollination deficits [38]. In fact, according to a review about the incidence of pollinating insects in tons produced per hectare, it was pointed out that within the study crops, the cucurbit family is the most susceptible to having a deficit in the quantity production due to inadequate pollination [38]. In this same sense, [37] a study on different pumpkin crops in Thailand found that a greater diversity of pollinators increases the number of individuals produced.

Despite all the positive effects on the quantity of yield mentioned above, our findings did not support these patterns, and other factors can be invoked to explain the lack of effect of treatments or pollinator species on the seed set. One of these is the fact that in both plots, A. mellifera was the most frequent pollinator species, which can result in similar pollen deposition and seed development in both treatments. Most of the differences in seed production have been found in studies in which wild pollinator diversity was greater than that of honeybees [36], which was not the case in our study. Other relevant factors include the adverse climatic conditions during the sampling season. Large heat waves, accompanied by the intense drought that occurred in the north and center of the country in the last decade [39], could have affected the secretion of floral reward [40], equally affecting pollinators' performance in both plots, and possibly altering seed development. Moreover, another relevant factor could be the sample size and/or the position of the selected plants within each plot. We selected only 20 individuals per plot, and they were mainly distributed in the first five rows (i.e., those closest to the floral patches), making the data obtained not sufficiently representative of the production of the entire orchard.

Finally, it is important to notice that although this study considered the entire flowering period of C. maxima (i.e., one month, during which the flowers remain open for 
just one day), only one season was analyzed, which prevented us from determining the generality of our results. However, this research represents a first advance in the study of the impact of increasing the diversity of flowering plants on the productivity of C. maxima in Chile. Likewise, it allows us to elucidate the importance of biodiversity for agricultural systems, and specially the role of pollinators, in the improved functioning and productivity of cropping systems. Undoubtedly, new studies are required that include orchards of different size areas, a greater number of individuals, experimental designs that incorporate a wide variety of native plants, and the measurement of different quality and quantity fruit variables to understand in a comprehensively way the plant-pollinator relationship applied in productive agricultural systems.

Author Contributions: M.M. conceived the study and designed the experiments. S.D. the executed the experiments and its monitoring. M.M. and S.D. analyzed the data. M.M. and S.D. wrote the manuscript. All authors have read and agreed to the published version of the manuscript.

Funding: This study was funded by the Chilean Agency of Research and Development (ANID), project ANID/PCI/NE/S011870/1. MM was supported by Fondecyt 11170377.

Institutional Review Board Statement: Not applicable.

Informed Consent Statement: Informed consent was obtained from all subjects involved in the study.

Data Availability Statement: The data are available under authors' request.

Acknowledgments: The authors are grateful to Fernanda Cortés for fieldwork assistance and Rodrigo Barahona for insect identification.

Conflicts of Interest: The authors declare no conflict of interest.

\section{References}

1. Garibaldi, L.A.; Carvalheiro, L.G.; Vaissière, B.E.; Gemmill-Herren, B.; Hipólito, J.; Freitas, B.M.; Ngo, H.T.; Azzu, N.; Sáez, A.; Åström, J.; et al. Mutually beneficial pollinator diversity and crop yield outcomes in small and large farms. Science 2016, 351, 388-391. [CrossRef] [PubMed]

2. Greenleaf, S.S.; Kremen, C. Wild bees enhance honeybees' pollination of hybrid sunflower. Proc. Natl. Acad. Sci. USA 2006, 103, 13890-13895. [CrossRef] [PubMed]

3. Petersen, J.D.; Reiners, S.; Nault, B.A. Pollination Services Provided by Bees in Pumpkin Fields Supplemented with Either Apis mellifera or Bombus impatiens or Not Supplemented. PLoS ONE 2013, 8, e69819. [CrossRef] [PubMed]

4. Bartomeus, I.; Potts, S.G.; Steffan-Dewenter, I.; Vaissière, B.E.; Woyciechowski, M.; Krewenka, K.M.; Tscheulin, T.; Roberts, S.P.M.; Szentgyörgyi, H.; Westphal, C.; et al. Contribution of insect pollinators to crop yield and quality varies with agricultural intensification. PeerJ 2014, 2, e328. [CrossRef]

5. Tuell, J.K.; Isaacs, R. Weather During Bloom Affects Pollination and Yield of Highbush Blueberry. J. Econ. Entomol. 2010, 103, 557-562. [CrossRef]

6. Klatt, B.K.; Holzschuh, A.; Westphal, C.; Clough, Y.; Smit, I.; Pawelzik, E.; Tscharntke, T. Bee pollination improves crop quality, shelf life and commercial value. Proc. R. Soc. B Biol. Sci. 2014, 281, 20132440. [CrossRef]

7. Button, L.; Elle, E. Wild bumble bees reduce pollination deficits in a crop mostly visited by managed honey bees. Agric. Ecosyst. Environ. 2014, 197, 255-263. [CrossRef]

8. Garratt, M.P.D.; Breeze, T.D.; Boreux, V.; Fountain, M.T.; McKerchar, M.; Webber, S.M.; Coston, D.J.; Jenner, N.; Dean, R.; Westbury, D.B.; et al. Apple Pollination: Demand Depends on Variety and Supply Depends on Pollinator Identity. PLoS ONE 2016, 11, e0153889. [CrossRef]

9. Miñarro, M.; García, D.; Sastre, R.M. Los insectos polinizadores en la agricultura: Importancia y gestión de su biodiversidad. Ecosistemas 2018, 27, 81-90. [CrossRef]

10. Ollerton, J.; Winfree, R.; Tarrant, S. How many flowering plants are pollinated by animals? Oikos 2011, 120, 321-326. [CrossRef]

11. Eilers, E.J.; Kremen, C.; Smith Greenleaf, S.; Garber, A.K.; Klein, A.-M. Contribution of Pollinator-Mediated Crops to Nutrients in the Human Food Supply. PLoS ONE 2011, 6, e21363. [CrossRef]

12. Bongaarts, J. IPBES, 2019. Summary for policymakers of the global assessment report on biodiversity and ecosystem services of the Intergovernmental Science-Policy Platform on Biodiversity and Ecosystem Services. Popul. Dev. Rev. 2019, 45, 680-681. [CrossRef]

13. Gallai, N.; Salles, J.-M.; Settele, J.; Vaissière, B.E. Economic valuation of the vulnerability of world agriculture confronted with pollinator decline. Ecol. Econ. 2009, 68, 810-821. [CrossRef]

14. Wratten, S.D.; Gillespie, M.; Decourtye, A.; Mader, E.; Desneux, N. Pollinator habitat enhancement: Benefits to other ecosystem services. Agric. Ecosyst. Environ. 2012, 159, 112-122. [CrossRef] 
15. Carvalheiro, L.G.; Veldtman, R.; Shenkute, A.G.; Tesfay, G.B.; Pirk, C.W.W.; Donaldson, J.S.; Nicolson, S.W. Natural and within-farmland biodiversity enhances crop productivity. Ecol. Lett. 2011, 14, 251-259. [CrossRef]

16. Barbir, J.; Badenes-Pérez, F.R.; Fernández-Quintanilla, C.; Dorado, J. Can floral field margins improve pollination and seed production in coriander Coriandrum sativum L. (Apiaceae)? Agric. For. Entomol. 2015, 17, 302-308. [CrossRef]

17. Feltham, H.; Park, K.; Minderman, J.; Goulson, D. Experimental evidence that wildflower strips increase pollinator visits to crops. Ecol. Evol. 2015, 5, 3523-3530. [CrossRef]

18. Carvalheiro, L.G.; Seymour, C.L.; Nicolson, S.W.; Veldtman, R. Creating patches of native flowers facilitates crop pollination in large agricultural fields: Mango as a case study. J. Appl. Ecol. 2012, 49, 1373-1383. [CrossRef]

19. FAO. Identificación de Sistemas de Producción Agrícola de Importancia Económica Impactados por la Zoopolinización. In Estado del Arte del Servicio Ecosistémico de la Polinización en Chile, Paraguay y Perú. 2017, p. 30. Available online: https: //www.fao.org/publications/card/en/c/c2114ea8-bd36-4aad-8c24-e5923bbe80f9/ (accessed on 20 May 2021).

20. Wien, H. (Ed.) The cucurbits: Cucumber, melon, squash and pumpkin. In The Physiology of Vegetable Crops; CAB International: Wallingford, UK, 1997; pp. 345-386.

21. Eguillor, P. El Mercado del Zapallo: Producción, Precios y Perspectivas. 2011, Volume 11. Available online: https://www.odepa. gob.cl/odepaweb/publicaciones/doc/3424.pdf (accessed on 20 May 2021).

22. Krarup, C.K.P. Hortalizas de Estaciones Cálidas. Available online: http://www7.uc.cl/sw_educ/hortalizas/html/zapallo/ zapallo.html (accessed on 20 May 2021).

23. RStudio Team. RStudio: Integrated Development for R; RStudio, PBC: Boston, MA, USA, 2021. Available online: http://www. rstudio.com/ (accessed on 20 May 2021).

24. Brittain, C.; Kremen, C.; Klein, A.-M. Biodiversity buffers pollination from changes in environmental conditions. Glob. Chang. Biol. 2013, 19, 540-547. [CrossRef]

25. Pisanty, G.; Afik, O.; Wajnberg, E.; Mandelik, Y. Watermelon pollinators exhibit complementarity in both visitation rate and single-visit pollination efficiency. J. Appl. Ecol. 2016, 53, 360-370. [CrossRef]

26. Muñoz, A.E.; Amouroux, P.; Zaviezo, T. Native flowering shrubs promote beneficial insects in avocado orchards. Agric. For. Entomol. 2021, 23, 463-472. [CrossRef]

27. Flores-Prado, L. Evolución de la sociabilidad en Hymenoptera: Rasgos conductuales vinculados a niveles sociales y precursores de sociabilidad en especies solitarias. Rev. Chil. Hist. Nat. 2012, 85, 245-266. [CrossRef]

28. Nicholls, C.I.; Altieri, M.A. Plant biodiversity enhances bees and other insect pollinators in agroecosystems: A review. Agron. Sustain. Dev. 2013, 33, 257-274. [CrossRef]

29. Blaauw, B.R.; Isaacs, R. Larger patches of diverse floral resources increase insect pollinator density, diversity, and their pollination of native wildflowers. Basic Appl. Ecol. 2014, 15, 701-711. [CrossRef]

30. Phillips, B.W.; Gardiner, M.M. Use of video surveillance to measure the influences of habitat management and landscape composition on pollinator visitation and pollen deposition in pumpkin (Cucurbita pepo) agroecosystems. PeerJ 2015, 3, e1342. [CrossRef]

31. Fountain, M.T.; Mateos-Fierro, Z.; Shaw, B.; Brain, P.; Delgado, A. Insect pollinators of conference pear (Pyrus communis L.) and their contribution to fruit quality. J. Pollinat. Ecol. 2019, 25, 103-114. [CrossRef]

32. Gajc-Wolska, J.; Kowalczyk, K.; Mikas, J.; Drajski, R. Efficiency of cucumber (cucumis sativus L.) pollination by bumblebees (Bombus terrestris). Acta Sci. Pol. Hortorum Cultus 2011, 10, 159-169.

33. Park, M.G.; Raguso, R.A.; Losey, J.E.; Danforth, B.N. Per-visit pollinator performance and regional importance of wild Bombus and Andrena (Melandrena) compared to the managed honey bee in New York apple orchards. Apidologie 2016, 47, 145-160. [CrossRef]

34. Eeraerts, M.; Vanderhaegen, R.; Smagghe, G.; Meeus, I. Pollination efficiency and foraging behaviour of honey bees and non-Apis bees to sweet cherry. Agric. For. Entomol. 2020, 22, 75-82. [CrossRef]

35. Sapir, G.; Baras, Z.; Azmon, G.; Goldway, M.; Shafir, S.; Allouche, A.; Stern, E.; Stern, R.A. Synergistic effects between bumblebees and honey bees in apple orchards increase cross pollination, seed number and fruit size. Sci. Hortic. (Amst.) 2017, 219, 107-117. [CrossRef]

36. Garibaldi, L.; Steffan-Dewenter, I.; Winfree, R.; Aizen, M.; Bommarco, R.; Cunningham, S.; Carvalheiro, L.; Harder, L.; Afik, O.; Bartomeus, I.; et al. Wild Pollinators Enhance Fruit Set of Crops Regardless of Honey Bee Abundance. Science 2013, 339, $1608-1611$. [CrossRef]

37. Hoehn, P.; Tscharntke, T.; Tylianakis, J.M.; Steffan-Dewenter, I. Functional group diversity of bee pollinators increases crop yield. Proc. R. Soc. B Biol. Sci. 2008, 275, 2283-2291. [CrossRef]

38. Garibaldi, L.A.; Aizen, M.A.; Cunningham, S.; Klein, A.M. Communicative \& Integrative Biology Pollinator shortage and global crop yield Looking at the whole spectrum of pollinator dependency. Commun. Integr. Biol. 2009, 2, 37-39. [CrossRef]

39. Garreaud, R.D.; Alvarez-Garreton, C.; Barichivich, J.; Boisier, J.P.; Christie, D.; Galleguillos, M.; LeQuesne, C.; McPhee, J.; Zambrano-Bigiarini, M. The 2010-2015 megadrought in central Chile: Impacts on regional hydroclimate and vegetation. Hydrol. Earth Syst. Sci. 2017, 21, 6307-6327. [CrossRef]

40. Takkis, K.; Tscheulin, T.; Petanidou, T. Differential Effects of Climate Warming on the Nectar Secretion of Early- and Late-Flowering Mediterranean Plants. Front. Plant Sci. 2018, 9, 874. [CrossRef] 